\title{
Recovery and Characterization of Oil from Waste Crude Oil Tank Bottom Sludge from Azzawiya Oil Refinery in Libya
}

\author{
Abdulatif A Mansur ${ }^{1,2 *}$, Muthu Pannirselvam ${ }^{3}$, Khalid A Al-Hothaly ${ }^{1,4}$, Eric M Adetutu ${ }^{1}$ and Andrew S Ball \\ ${ }^{1}$ School of Applied Sciences, RMIT University, Bundoora 3083, Australia \\ ${ }^{2}$ Environmental and Natural Resources Engineering, Faculty of Engineering, Azawia University, Libya \\ ${ }^{3}$ School of Civil, Environmental and Chemical Engineering, RMIT University, Melbourne 3000, Australia \\ ${ }^{4}$ Department of Biotechnology, Faculty of Science, Taif University, Kingdom of Saudi Arabia
}

\begin{abstract}
In this work we present the results of quantitative and qualitative analyses of oil obtained from crude oil tank bottom sludge (COTBS) generated from Azzawiya oil refinery in Libya. The aim of the study was to recover and evaluate oil from waste oily sludge and to compare it with parent oil (Hamada crude oil) in order to assess the commercial potential of recycling the oil. The benefits would be two-fold, firstly to improve oil utilisation efficiency and secondly in reducing the environmental contamination associated with the petrogenic hydrocarbon industry. Oily COTBS and extracted oil were characterised and key properties were measured including water and oil content, light and heavy hydrocarbon content, solid content and organic matter content for COTBS and water content, density, specific gravity, API (American Petroleum Institute) gravity, viscosity, salt and ash content for the extracted oil. Solvent (hexane) extraction confirmed that the oily sludge contained $42.08 \%( \pm 1.1 \%)$ oil composed of light hydrocarbons $(30.7 \pm 0.07 \%)$ and heavy hydrocarbon $(69.3 \pm 0.4 \%)$ fractions. The water and solid contents were $2.9 \%( \pm 0.2 \%)$ and $55.02 \%( \pm 0.6 \%)$ respectively. The properties of the recovered oil were assessed; gas chromatograph spectrophotometer (GC-MS) results indicated that the oil contained 139 different hydrocarbon fractions with a total petroleum hydrocarbon (TPH) concentration of $29,367 \mathrm{mgkg}^{-1}$ and a polycyclic aromatic hydrocarbons $(\mathrm{PAH})$ concentration of $11,752 \mathrm{mgkg}^{-1}$. Several parameters of the oil were measured and compared to the parent oil (Hamada crude oil) including density, specific gravity, viscosity, salt and ash content. The API of the extracted oil (33.03) was lower than the parent oil (38.8) due to a reduced light hydrocarbon (LHC) content. TGAFTIR hyphenation shows both mass loss of hydrocarbons - low, medium and high molecular mass over a range of temperatures between $60^{\circ} \mathrm{C}$ and $450^{\circ} \mathrm{C}$. crude oil extract exhibited a non-Newtonian behaviour (shear thinning) for the shear rate sweep between 10 and 500/s. dynamic shear rheology data showed that the extracted oil exhibit more like a solid than liquid. Overall the findings of the study confirmed that COTBD has a significant amount of oil similar in properties to Hamada crude oil. This large amount can be reclaimed and recycles. Depending on this essay, a commercial process could be performed which in parallel will reduce the environmental contamination with hydrocarbons.
\end{abstract}

Keywords: Solvent extraction; Oil recovery; Total petroleum hydrocarbon; Hyphenation; Dynamic shear rheology; Shear thinning; Storage modulus; Loss modulus; Thermogravimetry

\section{Introduction}

Petroleum crude oil represents one of the main current sources of energy. With the continuous increase in world population and industrialization, there is an increase in the global demand for petroleum crude oil and downstream products. In July 2012, Endurance International Group, Inc. (EIG) reported total global crude oil stocks of 7148 million barrels, with an estimation daily flow of oil production of around 75 million barrels [1]. In the processing of this crude oil the oil industry annually generates massive quantities of oily sludge during the different crude oil operations from exploration to refining [2]. The largest amount of the oily sludge is generated in oil refineries during oil storing operations. Most of the crude oil storage tanks contain bottom settling sediments accumulated over the time which are called crude oil tank bottom sludge (COTBS). During the cleaning processes, all the waste (COTBS) is removed and dumped in designated ponds. The continuous generation of COTBS during the bulk storage of crude oil is an unavoidable phenomenon [3]. COTBS usually contains a significant amount (30-50\%) of oil (heavy hydrocarbons) [4], in addition to water $(30-50 \%)$ and solids $(10-12 \%(w / v)$ [5]. However, the global composition of COTBS is highly variable varying from one facility to another and from tank to tank within the same facility. COTBS composition is dependent on the composition of the stored oil, storage conditions, storage period and the design and mechanical conditions of the storage tank [6].

Due to the accumulation of large quantities of COTBS together with its hazardous nature and associated waste management difficulties, COTBS has become a critical problem in most oil refineries [7]. In 2001, the USA petroleum industry was estimated to generate about $1.5 \times 10^{6}$ barrels of COTBS per annum [8] while large oil refineries (processing $2-5 \times 10^{5}$ ) barrels/day were estimated to produce $10 \times 10^{3}$ $\mathrm{m}^{3}$ per year [9] . In India, petroleum oil refineries generate around $50 \times$ $10^{3}$ tonnes $(\mathrm{t})$ per annum of oil rich COTBS (30-40\% oil) [7]. In China, the petrochemical industry discharges nearly $3 \times 10^{6} \mathrm{t}$ of COTBS per annum. One third of this amount $\left(1 \times 10^{6} \mathrm{t}\right)$ was derived from cleaning

*Corresponding author: Abdulatif A Mansur, School of Applied Sciences, RMIT University, Bundoora3083, Australia, Tel: 86-13698705584; Email: S3370890@student.rmit.edu.au, mansour2001uk@yahoo.com

Received January 30, 2015; Accepted March 09, 2015; Published March 16 2015

Citation: Mansur AA, Pannirselvam M, Al-Hothaly KA, Adetutu EM, Ball AS (2015) Recovery and Characterization of Oil from Waste Crude Oil Tank Bottom Sludge from Azzawiya Oil Refinery in Libya. J Adv Chem Eng 5: 118. doi: 10.4172/20904568.1000118

Copyright: (c) 2015 Mansur AA, et al. This is an open-access article distributed under the terms of the Creative Commons Attribution License, which permits unrestricted use, distribution, and reproduction in any medium, provided the original author and source are credited. 
operations associated with crude oil storage tanks [10]. In parallel with oil refineries, oilfields also generate significant amounts of COTBS. In 2010, Shengli Oilfield alone discharged more than $10 \times 10^{4} \mathrm{t}$ of COTBS [11].

The accumulation of COTBS inside the oil tanks reduces their oil storing capacities and introducing the oily sludge into the refinery can ultimately disturb the refining processes [12]. In contrast, spilling of COTBS in the environment without treatment poses a significant risk to the surrounding environment and population. Importantly, prolonged storage of COTBS in accumulation ponds leads to seepage and contamination of ground water as well as the reduction in the light (volatile) fractions. Many of these volatile compounds are known of suspected carcinogens and mutagens and their release into the air poses a significant threat to the ecosystem and human population. Moreover, If COTBS is disposed of inappropriately, the oily sludge will splash into the soil where hundreds of individual compounds will contaminate the soil $[11,13,14]$. As many of COTBS hydrocarbon components are considered as toxic, mutagenic or carcinogenic [15], in 1992 the United States Environmental Protection Agency (US EPA) announced a final rule $(57$ FR 37194, 37252) stating treatment regulations and standards under the land disposal restrictions program for several hazardous wastes including hydrocarbon materials (COTBS) [16].

COTBS is continuously generated and disposed of in large quantities [17]. Recently, development of treatment strategies for COTBS to reduce their environmental burden has received increased global attention [4] and different effective remediation techniques have been proposed [17] including physical, chemical and biological methods. Among the techniques described, landfilling, incineration, microwave liquefaction, centrifugation, encapsulation, biodegradation in landfarming, biopiles and bioreactors have all featured [18]. However, some methods (e.g. incineration) have become restricted in some countries through the implementation of rigorous environmental standards because of their potential environmental impact [19].

Given the high hydrocarbon content of the oily COTBS, the conventional treatment methods such as land farming, landfilling and incineration are time-consuming, ineffective, expensive and may potentially release more unwanted environmental pollutants $[20,21]$. Also as oily COTBS is recognized as a potentially valuable energy resource, decomposition (bioremediation) techniques using microorganisms are also inadvisable [21]. The current driving force for increased interest in studying and characterising the COTBS are to recover oil from waste oily sludge in order to assess the commercial potential of recycling the oil. The benefits would be two-fold, firstly to improve oil utilisation efficiency and secondly in reducing the environmental contamination associated with the petrogenic hydrocarbon industry $[22,23]$.

To characterise and classify recovered oil for commercial use, its physiochemical properties should be known. To classify the oil, the API gravity is the most important property. It is the relative density of the petroleum liquids and the density of water, and used to compare the relative densities of petroleum products. API is a scale for denoting the 'lightness' or 'heaviness' of petroleum crude oils and products. The lighter hydrocarbon the higher API gravity and the lighter hydrocarbon the higher market value. Oils with API more than $30^{\circ}$ are known as light while oils in the range between $22^{\circ}$ and $30^{\circ}$ are medium, but API less than $22^{\circ}$ are heavy and below $10^{\circ}$ are extra heavy. It is preferable to between $25^{\circ}$ and $30^{\circ}$ [24]. In addition to the density, the viscosity which is the resistance to flow is another important factor that affects the pumping and transportation abilities through the pipelines. Dealing with high viscosity oil is one of the main difficulties in transportation through the piping network [25]. Usually the viscosity of hydrocarbon oils ranges from $100 \mathrm{mPa}$ to $10^{5}$ $\mathrm{mPa}$ and the maximum desired viscosity is $400 \mathrm{mPa}$ [26], but the high viscosity can be reduced to the desired value by reducing the liquid temperature by adding gaseous or liquid diluents [25]. In addition, flash point which is the minimum temperature at which the vapours of the material can ignite is the indicator of the flammability of the hydrocarbon oils. Safe handling of oils including processing, storage and transportation needs knowing the accurate values of flash point [27]. Moreover; presence of ash in the oil can affect the quality of oil. The ash content provides knowledge of metallic constituent left after complete combustion of the oil under specific condition. High ash content lowers the heating values and it is undesirable for direct combustion due to fouling and slagging [28]. Usually the petroleum crude oil contains a small amount of salts expressed as the presence of $\mathrm{NaCl}$. If the salt content is higher the $1000 \mathrm{bbl}$, the salt need to be minimized to reduce the fouling and corrosion in addition to the formation of acids by salts chlorides [29].

Therefore this work aims to assess the quality of recovered oil from waste oily sludge and to compare it with parent oil (Hamada crude oil) for recycling purposes and (ii) to reduce the environmental impact of COTBS by reducing the oil content of the soil to the minimum possible levels.

\section{Materials and Methods}

\section{Characterization of sludge}

Petroleum-based COTBS samples used for this study were obtained from collection lagoons at Azzawiya oil refinery in Libya. After collection, the sludge samples were kept at room temperature for the duration of the study. The sludge was mixed well manually before each sample was taken.

Water content (wt\%): The water content of the COTBS samples was measured as indicated by the American Society for Testing and materials (ASTM) standard method (D95). COTBS samples (25 g, in triplicate) were taken and placed in an extraction thimble and $75 \mathrm{ml}$ of dichloromethane (DCM) (solvent) were added (1:3 soil: solvent ratio) [30].The oil, solvent and water were then distilled and the condensate (water and solvent) continuously separated in a trap and transferred to a graduated cylinder. The triplicate condensates were pooled together [31]. It should be noted that due to the density of water $\left(1 \mathrm{~g} / \mathrm{cm}^{3}\right)$ being less than the density of solvent, the solvent layer settled at the bottom of the separation funnel and was measured.

Volatile hydrocarbons and moisture content (wt\%): Volatile hydrocarbons $(\mathrm{VH})$ and moisture content of the COTBS samples were determined in triplicate by weighing $(8 \mathrm{~g})$ in ceramic crucibles and heating to $105^{\circ} \mathrm{C}$ in a ventilated incubator for $24 \mathrm{~h}$. The lost mass was attributed to light volatile hydrocarbons and moisture content [32]. The light volatile hydrocarbons were calculated using the following equation:

$$
\text { Light hydrocarbons }=\frac{\text { reduced mass }(\mathrm{g})}{\text { mass of tested sample }(\mathrm{g})} \times 100 \% \text {-water }
$$$$
\text { content (\%) }
$$

Solid content (wt\%): Solid materials (sediment, ash and organic) content were measured according to the method described by [2] with some adjustments. After measuring the light hydrocarbons and moisture content, the dried COTBS samples $\left(\right.$ at $\left.105^{\circ} \mathrm{C}\right)$ were heated in a muffle furnace (LABEC, Laboratory Equipment. Pty Ltd, Australia) 
to $550^{\circ} \mathrm{C}$ for $30 \mathrm{~min}[32]$ and the remaining samples re-weighed. The solid (sediment and ash) content of the COTBS was calculated using the following equation:

$$
\text { Solid content }=\frac{\text { reduced mass }(\mathrm{g})}{\text { mass of tested sample }(\mathrm{g})} \times 100 \%
$$

Organic matter content: The organic matter concentration was measured by loss on ignition of dry solid material in the muffle furnace $\left(550^{\circ} \mathrm{C}\right.$ for $\left.30 \mathrm{~min}\right)$. The mass that was lost by the sample was attributed to organic material.

Non-volatile hydrocarbons content (wt\%): Non-volatile hydrocarbons (NVH) was calculated according to [32] using the following equations:

\section{$\mathrm{NVH}=100 \%-\mathrm{VH}+\mathrm{SC}+\mathrm{WC}$}

Where: $\mathrm{NVH}$ is non-volatile hydrocarbons (wt\%)

$\mathrm{VH}$ is volatile hydrocarbons ( $\mathrm{wt} \%$ )

$\mathrm{SC}$ is solid content (wt\%)

WC is water content (wt\%)

Oil recovery: Oil was recovered from 6 sludge samples by solvent extraction (dichloromethane (DCM)) using a previously described protocol [30]. Briefly, a known amount $(74.3 \mathrm{~g}, 76.1 \mathrm{~g}, 71.00 \mathrm{~g}, 67.5 \mathrm{~g}$, $70.6 \mathrm{~g}$ and $67.1 \mathrm{~g}$ ) of COTBS samples were weighed at room temperature and placed in Teflon coated $(250 \mathrm{ml})$ centrifuge tubes and (DCM) was added (1:1 soil: solvent ratio). The oil in this mixture was extracted by agitation ( $130 \mathrm{rev} \mathrm{min}^{-1}$ ) for $30 \mathrm{~min}$, followed by centrifugation at 5000 rev $\mathrm{min}^{-1}$ for $5 \mathrm{~min}$. The supernatants containing oil and solvent were removed and collected into glass bottles $(500 \mathrm{ml})$.

Solvent recovery: To concentrate the reclaimed oil, the solvent (DCM) soluble fraction was rotary evaporated $(250 \mathrm{ml}$ a time $)$ in a Buchi 461 water bath (Buchi RE111 Rotavapor, Buchi, Switzerland) at $40^{\circ} \mathrm{C}$. The remaining oil was measured and reported as the volume of oil content in the COTBS and prepared for further analysis $[33,34]$.

\section{Characterization of recovered oil}

Determination of hydrocarbon fractions concentration: For the analysis of hydrocarbons fractions within the recovered oil, including aromatic and aliphatic compounds, a combined paraffins, isoparaffins, aromatic, naphthalenes and oleffins (PIANO) PIANO-5-Piano (DHA) standard combined set (2 $\mathrm{ml}$ ampule) (Spectrum Quality Standards, Ltd. Sugarland, TX, USA) was used. The hydrocarbon content of the extracted oil was analysed as described in ASTM D513 [30] using gas chromatograph mass spectrometer (GC-MS) equipped with autosampler (Aglient 6890 GC and Leco Pegasus III TOF-MS). Samples were injected and separated on a capillary column Agilent DB-5MS (60 $\mathrm{m}$ by $0.25 \mathrm{~mm}$ with $0.25 \mu \mathrm{m}$ film thickness). The injection temperature and volume was $225^{\circ} \mathrm{C}$ and $0.2 \mu$ respectively. Helium $\left(1.8 \mathrm{ml} \mathrm{min}^{-1}\right)$ was used as a carrier gas at a constant flow rate. The concentration of each hydrocarbon fraction was analyzed and the total peak area of each fraction was compared to the peak area of each fraction in the PIANO standard curve [35].

Density: The density $(\rho)$ of extracted oil was estimated by dividing a known mass of the oil to its volume. Briefly, $10 \mathrm{ml}$ of the recovered oil was measured and weighed (Mettler AE 260, Mettler-Toledo, Switzerland). The density of the oil was derived from the following equation:

$$
\rho=\text { mass } / \text { volume }
$$

Specific gravity: Specific gravity ( $\mathrm{SG}_{\text {true }}$ ) is the ratio of the density of a liquid to the density of water $(\mathrm{g} / \mathrm{l})$. The specific gravity of the claimed oil was measured according to [36] and can be expressed mathematically from the following equation:

$$
\mathrm{SG}_{\text {true }}=(\tilde{\mathrm{n}} \text { sample }) /(\tilde{\mathrm{n}} \mathrm{H} 2 \mathrm{O})
$$

API gravity: API gravity was calculated using the specific gravity of the oil extract, a unit-less property and determined at $60^{\circ} \mathrm{F}$. API gravity was calculated according to [37] using the following equation:

$$
\text { API gravity }=(141.5 / \text { Specific Gravity })-131.5
$$

Viscosity: Viscosity (v) was measured using a Cannon-Fenske (Fisher Scientific, Pittsburgh, PA) glass capillary kinematic viscometer in a constant temperature bath in accordance with ASTM D445. Kinematic viscosity is determined by measuring the time $(t)$ for a known volume of liquid flowing under gravity to pass through a calibrated glass capillary viscometer tube. The manufacturer of the Cannon- Fenske type viscometer tubes supplied calibration constants (c) at a range of temperature $40^{\circ} \mathrm{F}$ and $100^{\circ} \mathrm{F}[38,39]$.

Kinematic viscosity $(v)$ in centistoke $(c S t)$ was calculated from the following equation.

$v=c . t(7)$

Ash content: Ash content of the extracted oil was determined using a loss-on-ignition procedure according to [40] with some adjustments. Triplicate samples $(5 \mathrm{~g})$ were heated overnight at $105^{\circ} \mathrm{C}$ and then transferred to a muffle furnace held at $550^{\circ} \mathrm{C}$ for $30 \mathrm{~min}$ to burn the organic matter. Ash content was calculated from the ratio of pre- and post-ignition sample mass.

Salt content: The salinity of the extracted oil was determined using the electrometric method according to ASTM D 3230 procedures using a Pro 2030 multimeter (YSI Incorporation, Yellow Springs. OH 45387. USA). In this method, the sample was dissolved in a mixed solvent and placed in a test cell consisting of a beaker and two parallel stainless steel plates. An alternating voltage was passed through the plates, and the salt content was obtained by reference to a calibration curve of the relationship of salt content of known mixtures to the current $[41,42]$.

Thermogravimetric analysis (hyphenation with FTIR spectroscopy): The sample (COTBS extract) was used to measure mass loss and to determine functional group of the sample at a given time and temperature. Wilkie previously described a TGA/FTIR hyphenation technique that could be applied to investigate the degradation of crude oil extract [43]. Thermogravimetric analysis was performed on STA6000 operating under nitrogen with a flow rate of $20 \mathrm{ml} / \mathrm{min}$ through the furnace in the following conditions. A sample mass of $\sim 40 \mathrm{mg}$ was heated in the crucible with heating rate of $20^{\circ} \mathrm{C} / \mathrm{min}$ from 50 to $950^{\circ} \mathrm{C}$ in an inert atmosphere (nitrogen). The gas evolving from STA6000 was transferred via gas transfer line. This transfer line allows the transfer of combustion of pyrolysis products from thermal analyser to FTIR 100 through the gas flow cell. Spectrum time base was used to analyse the sp files collected during the testing to analyse the spectrum (collected continuously for over $3600 \mathrm{~s}$ ).

Shear rheology testing to measure viscosity: HR3 (Hybrid Discovery) rheometer was used to measure the rheological properties of sample (COTBS extract). The instrument (HR3 rheometer) was calibrated with viscosity standard including Polydimethyl Siloxane (PDMS). Crossover frequency of G' and G' of calibration results matched with the value recommended by instrument suppliers-TA instruments. Shear rheology was conducted on the sample at a constant 
temperature of $50^{\circ} \mathrm{C}$ and a constant strain of $1 \%$, angular frequency of 1 to $100 \mathrm{rad} / \mathrm{s}$. Parallel plate geometry ( $40 \mathrm{~mm}$ smart swap, stainless steel) was used in this research. It should be noted that the sample was tested as received.

\section{Results}

\section{Composition of the oily sludge}

Several key properties of the sludge were analysed and indicated in Table 1. The water content of the sludge was $2.9( \pm 0.2 \%)$ and the solid content was $55.02( \pm 0.6 \%)$. The amount of organic material in the solid content was found to be $70( \pm 0.6 \%)$ of the original dry mass of the sludge. Solvent extraction of the hydrocarbon oil from COTBS using dichloromethane (DCM) showed that the sludge contained a significant amount of oil (oil content $42.08 \pm 1.1 \%$ ) compsed of light (volatile) hydrocarbon $(\mathrm{VH}, 30.7 \pm 0.07 \%)$ and non-volatile hydrocarbons $(\mathrm{NVH}, 69.3 \pm 0.4 \%)$.

\section{Composition of recovered oil}

In addition to the amount of oil recovered, the quality of the oil has a major influence on determining the commercial viability of the recycling process. Selected physiochemical properties of the recovered oil from COTBS were tested including water content, organic material, density, specific gravity, API gravity, viscosity, salt content and ash content. The selected properties were compared with parent oil

\begin{tabular}{|l|c|}
\hline Property \% & Sludge \\
\hline Water content & $2.9 \pm 0.2$ \\
\hline Oil content & $42.08 \pm 1.1$ \\
\hline Light hydrocarbons and moisture content in the recovered oil & $30.7 \pm 0.07$ \\
\hline Non-volatile hydrocarbons in the recovered oil & $69.3 \pm 0.4$ \\
\hline Solid content & $55.02 \pm 0.6$ \\
\hline Organic matter content in solids & $70 \pm 0.6$ \\
\hline
\end{tabular}

Table 1: Properties of studied sludge.

\begin{tabular}{|l|c|c|}
\hline Property & $\begin{array}{c}\text { Extracted oil from } \\
\text { sludge }\end{array}$ & $\begin{array}{c}\text { Hamada petroleum } \\
\text { crude oil }\end{array}$ \\
\hline Water & - & 0.1 \\
\hline Density @ $15^{\circ} \mathrm{C}, \mathrm{g} / \mathrm{ml}$ & 0.86 & 0.8304 \\
\hline Specific gravity@60/60 $\mathrm{F}$ & 0.86 & 0.8311 \\
\hline API gravity & 33.03 & 38.8 \\
\hline Viscosity@70 $\mathrm{F}, \mathrm{cSt}$ & 7.01 & 6.8431 \\
\hline @100 $\mathrm{F}, \mathrm{cSt}$ & 3.655 & 3.5742 \\
\hline Salt content $($ as $\mathrm{NaCl}) \mathrm{mg} / \mathrm{l}$ & 2.30 & 2.14 \\
\hline Ash content $\mathrm{g} / \mathrm{g}$ oil & 0.007 & 0.004 \\
\hline
\end{tabular}

Table 2: Properties of extracted oil from COTBS and Hamada petroleum crude oil.

\begin{tabular}{|c|c|c|}
\hline Parameter & Importance & Reference \\
\hline Water content & $\begin{array}{l}\text { Increases the process pressure due to steam } \\
\text { formation }\end{array}$ & [57] \\
\hline High viscosity & $\begin{array}{l}\text { Resist to flow, required more energy for pumping } \\
\text { and decreases the heat transfer efficiency }\end{array}$ & [59] \\
\hline High density & $\begin{array}{l}\text { Resist to flow and requires more energy for } \\
\text { pumping }\end{array}$ & [58] \\
\hline API gravity & Indication of oil grade and quality & {$[58]$} \\
\hline Salt content & $\begin{array}{l}\text { High salt content causes corrosion and fouling } \\
\text { of process equipment and hydrolysed to } \\
\text { hydrochloric acid }\end{array}$ & [70] \\
\hline Ash content & Decreases the heat value & [28] \\
\hline Solid content & Increase the viscosity & [2] \\
\hline
\end{tabular}

\begin{tabular}{|l|l|}
\hline Temperature & Major compound evolving from the sample at that temperature \\
\hline $170^{\circ} \mathrm{C}$ & Methylene Chloride \\
\hline $410^{\circ} \mathrm{C}$ & trans-1,4-dimethylcyclohexane \\
\hline $450^{\circ} \mathrm{C}$ & Cyclohexane 1-hexyl 4-tetradecyl \\
\hline $570^{\circ} \mathrm{C}$ & Isobutyl cyclo-hexane \\
\hline $770^{\circ} \mathrm{C}$ & 1-ethyl 2-methylcyclohexane \\
\hline
\end{tabular}

Table 4: Gases evolving at various temperatures during hyphenation studies.

(Hamada crude oil) properties are summarized in Tables 2 and 3. GCMS based analysis of the recovered oil resulted in up to 136 different hydrocarbon fractions being detected including aromatic compounds (45.6\%) and aliphatic compounds (34.6\%) with some of these fractions (19.8\%) being undefined (Figure 1). The concentrations of TPH and PAHs were $29,367 \mathrm{mgkg}^{-1}$ and $11,752 \mathrm{mgkg}^{-1}$ respectively. API gravity was calculated mathematically after determining the density of the oil $\left(0.68 \mathrm{gl}^{-1}\right)$ and was 33.03, confirming that this oil was as light as the parent oil. In addition, the kinematic viscosity of the recovered oil measured at $70^{\circ} \mathrm{F}$ and $100^{\circ} \mathrm{F}$ was $(7.01$ and $3.655 \mathrm{cSt})$ respectively. According to the loss in ignition results, the ash content of this oil was $0.007 \mathrm{~g} / \mathrm{g}$ oil. Finally, the salinity test (as $\mathrm{NaCl}$ content) of the examined oil indicated that the salt content was $2.30 \mathrm{mgl}^{-1}$.

\section{Thermogravimetric analysis}

Mothe et al. [44] concluded that the study of thermogravimetry of crude oil based materials is very complicated due to the presence of many complex constituents [44]. In this research, we applied a hyphenation technique to analyse the gas evolving from the sample during thermogravimetric analysis (Table 4 ). The crude oil was exposed to a nitrogen atmosphere at heating rate of $20^{\circ} \mathrm{C} / \mathrm{min}$ for $45 \mathrm{~min}(2700$ s) from 50 to $950^{\circ} \mathrm{C}$.

\section{Rheology section}

The International Energy Agency reported that heavy crude oil represents over $50 \%$ of the world's recoverable oil resources. Crude oil is a composition of large amount of hydrocarbons and varying amount of waxes. Ghannam stated the dynamic shear rheology test is a rheological investigation to study the viscoelastic behaviour of crude oil [45]. Rheological properties for petroleum oils are very useful for all processes in which fluids are transferred from one location to another. Evdokimov et al concluded that limited numbers of crude oil rheological properties are currently available, in particular for heavy crude oil [46].

The dynamic frequency sweep test shows the effect of oscillating stresses on this extracted crude oil. The storage modulus exhibits solid behaviour of sample and loss modulus exhibits liquid behaviour of samples. Storage modulus shows the contribution of stress energy that is stored during the test and can be recovered. As a standard procedure, linear viscoelastic region of sample was studied of the sample using strain sweep test (in dynamic mode). Three tests of the above mentioned methodology was conducted to check the reliability of the measured data. The rheograms matched well within the tolerance limits of about $\pm 3 \%$.

\section{Discussion}

Due to the undesirable environmental impact of dumping COTBS with high hydrocarbon content and the economic benefits of the COTBS as a source of petroleum oil, there is current interest in studying the quantitative and qualitative characteristics of COTBS and the recovered oil. The management of oily wastes involves the analysis and characterization of both recovered oil and sludge. Knowing the 


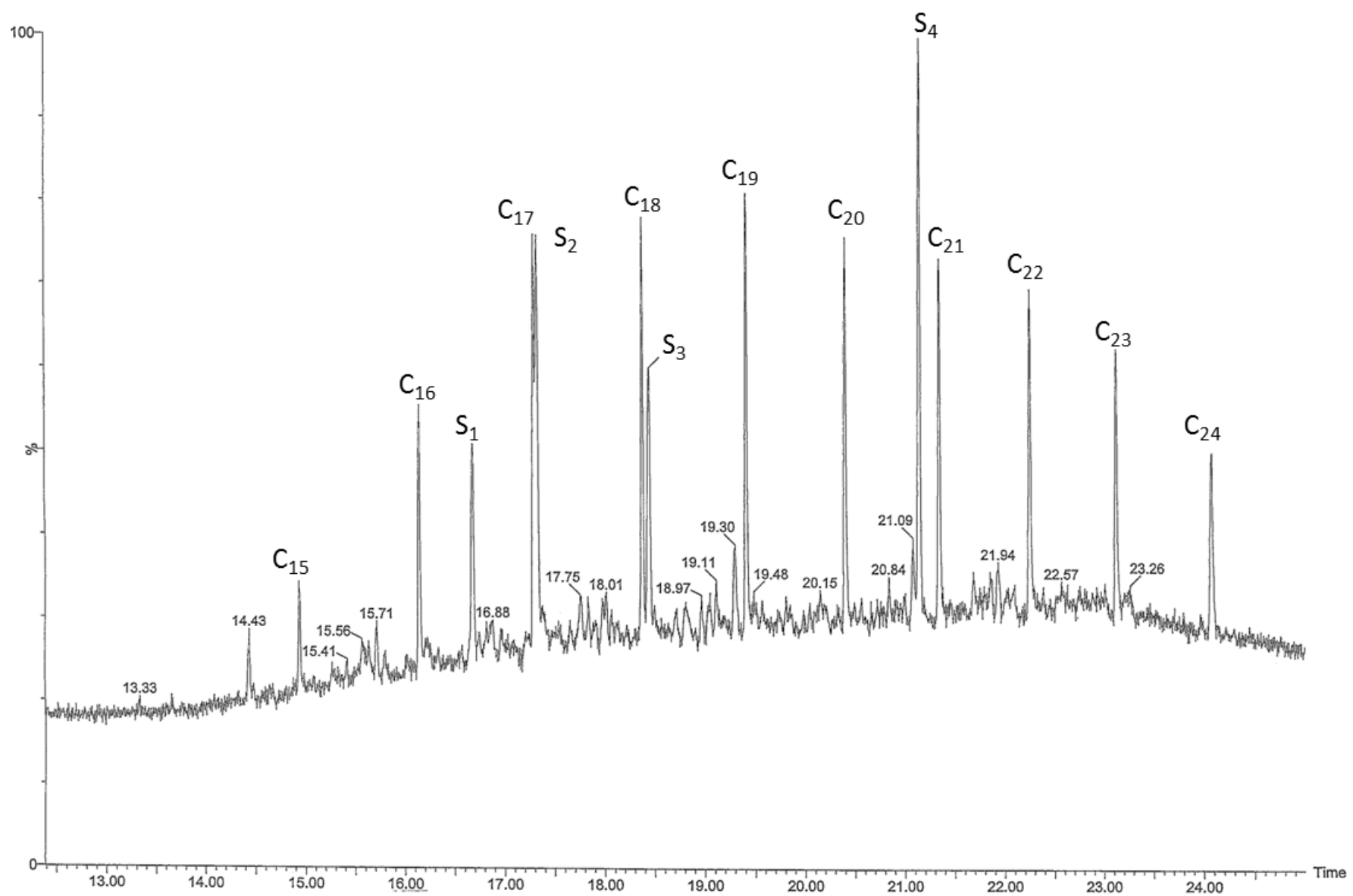

Figure 1: GC-MS chromatogram of oil extracted from COTBS with some selected peaks identified. S1 2,6,10-trimethyldodecane, S2 2,6,10,14-tetramethylpentadecane, S3 2,6,10,14-tetramethylhexadecane, S4 cyclic octa-atomic sulphur.

amounts produced, physical and chemical properties of sludge are important parameters in defining the applied conventional treatment strategies [18]. For the recovered oil, quantitative and qualitative assessment represents the most important parameters in determining the applicability of the oil for use as crude or fuel oil. In this research, the results of the studied COTBS showed that the average water content was low (2.9\%). This low water content percentage was expected because the sludge studied in this research has been accumulated for several years and the water was separated into the bottom of the collection ponds due to the density difference between water and sludge. Comparing with other sludges, this percentage was very low. Heidarzadeh et al. [47] showed that the water content of a studied COTBS obtained from Iran refinery was $28.3 \%$. Similarly, other research [48] determined the water content of 2 different oily sludges in China and found a significant amount of water (16.2 and 27.6\%). On the basis of dry mass, the solid content of the oily sludge was $55.02 \%$, of which $70 \%$ was organic matter. This relatively high solid content was expected since the stored COTBS was not exposed to a solid removal process. The presence of solid materials including sand and rust significantly increases the sludge viscosity [2,48]. Extraction of the oil from COTBS using a 1:1 ratio of COTBS: solvent revealed a high oil content $(42.08 \%)$ of which with $29.7 \%$ were VH and $70.3 \% \mathrm{NVH}$. This oil could be potentially extracted and recycled. Recovering and recycling of valuable hydrocarbon oils aids the conservation of environment and energy resources $[2,49]$ and decreases the consumption of non-renewable energy resources [50].
According to the American Petroleum Institute (USAPI), the primary environmental consideration in handling oily sludge is the maximum hydrocarbon recovery [51]. In the oil refining industry in the USA, more than $80 \%$ of the generated waste hydrocarbons were recycled while the remaining (20\%) were disposal according to the (EPA) standards [52]. Generally, some studies suggested that high oil concentrations in COTBS $(>50 \%)$ and a relatively low concentration of solids $(<30 \%)$ are preferable for recycling [53]. Others suggested that even at low COTBS oil content $(>10 \%)$, oil recovery is still accepted [7]. In this study, within the extracted oil (42.08\%), the light hydrocarbon fractions (LHF) were not very high because of evaporation since the collection ponds were exposed to the environmental elements (wind, sun, etc) for many years. A similar study on exposed COTBS [47] indicated that the LHF was also very low $(<10 \%)$. Storing COTBS in closed facilities results in increased volatile fractions [32] studied COTBS obtained from the Niger delta, Nigeria and determined the oil content to be $73.24 \%$, of which $45.84 \%$ were light hydrocarbons. Light hydrocarbon fractions are important in qualifying the oil grade. The presence of (LHF) decreases the density and viscosity and increases the API of the oil. Hu et al. [4] reported that the oil content in COTBS range from $5 \%$ to $86.2 \%(\mathrm{w} / \mathrm{v})$, although oil content in the range of $15-50 \%(\mathrm{w} / \mathrm{w})$ was more frequent while the solids and water contents were in the range of $5-46 \%(\mathrm{w} / \mathrm{w})$ and $30-85 \%$ $(w / w)$ respectively. Increasing the solvent:sludge ratio could increase the amount of recovered oil. Zubaidy and Abouelnasr [2] studied various ratios and found that (4:1) solvent:sludge ratio facilitated the extraction 
of the highest amount of oil. Zubaidy and Abouelnasr [2] studied the solvent extraction of hydrocarbon compounds and found that heavy molecular mass hydrocarbons were extracted more when less solvent was used. However, increasing the solvent:sludge ratio is not economical as most of the solvents used are expensive; in addition, in low condensation efficiencies, large amounts of solvent could not be reclaimed. Moreover, since the solid content was high (55.02\%), a large amount of solvent will be adsorbed within the porous particles. The solvent path within a porous media depends largely on pore size; the more porous media the less solvent reclaimation back [54]. Consequently, 1:1 solvent: sludge ratio is recommended for reclamation and economic purposes.

In addition to the amount of oil recovered, the quality of the oil is also a major concern. A set of oil grading physiochemical properties were conducted. Comparing with properties of Hamada crude oil, some properties of the recovered oil were higher including density, specific gravity $(S G)$, viscosity, salt content and ash content; in contrast, water content and API gravity were less than those of Hamada crude oil (Table 2). Gas chromatographic mass spectrophotometer (GCMS) analysis of the extracted oil showed the presence of a range of hydrocarbon fractions composed of 136 different compounds ranging from $\mathrm{C}_{14}-\mathrm{C}_{24}$ (Figure 1) including both aromatic $(45.6 \% \mathrm{v} / \mathrm{w})$ and aliphatic compounds $(34.6 \% \mathrm{v} / \mathrm{w})$ with $19.8 \%$ being undefined. The total petroleum hydrocarbon $(\mathrm{TPH})$ concentration of the recovered oil was $29,367 \mathrm{mgkg}^{-1}$ and polycyclic aromatic hydrocarbon (PAH) concentration was $11,752 \mathrm{mgkg}^{-1}$. For comparison, [55] conducted a similar study on COTBS and found that the TPH of extracted oil was higher than $29,367 \mathrm{mgkg}^{-1}\left(500,000 \mathrm{mgkg}^{-1}\right)$, while another study found the TPH of an extracted oil to be very low $\left(850 \pm 150 \mathrm{mgkg}^{-1}\right)$ [31]. Water content analysis indicated that the extracted oil was free of water. The presence of water lowers the heating value of the oil [56]; in addition, it generates steam and builds pressure in the refining processes [57]. The density of the oil was measured and found to be 0.86 which was higher than the density of the parent oil. Also, the $S G$ has also been calculated at $60^{\circ} \mathrm{F}$ and found to be higher $(0.86)$ than the original crude oil. Depending on the $S G$ of the extracted oil, the mathematical calculation results show the API density to be 33.03. The API density is one of the main parameters used to grade the crude oil. Martínez-Palou et al. [58] indicated that oil with $\mathrm{API}<10$ is classified as extra heavy while API $<22.3$ is heavy, API 22.3 to 31.1 is medium and API $>31.1$ is light. The lighter the oil is the higher content of light hydrocarbon compounds, and the less wax and asphaltenes are present. Viscosity is the resistance to flow and a measure of the internal molecular fraction of the fluid and is an important parameter affecting the pumping of oil and atomization of fuel [59]. The kinematic viscosity of the extracted oil was measured at 2 different temperatures and compared to that of Hamada crude oil. At $60^{\circ} \mathrm{F}$ viscosity was $7.01 \mathrm{cSt}$ and at $100^{\circ} \mathrm{F}$ was 3.655 cSt while the viscosity of the Hamada oil was lower (6.8431 cSt and $3.5742 \mathrm{cSt}$ ) respectively. Lower LHF content in the oil increases the density and viscosity of the oil. Consequently more power is needed for pumping [59].

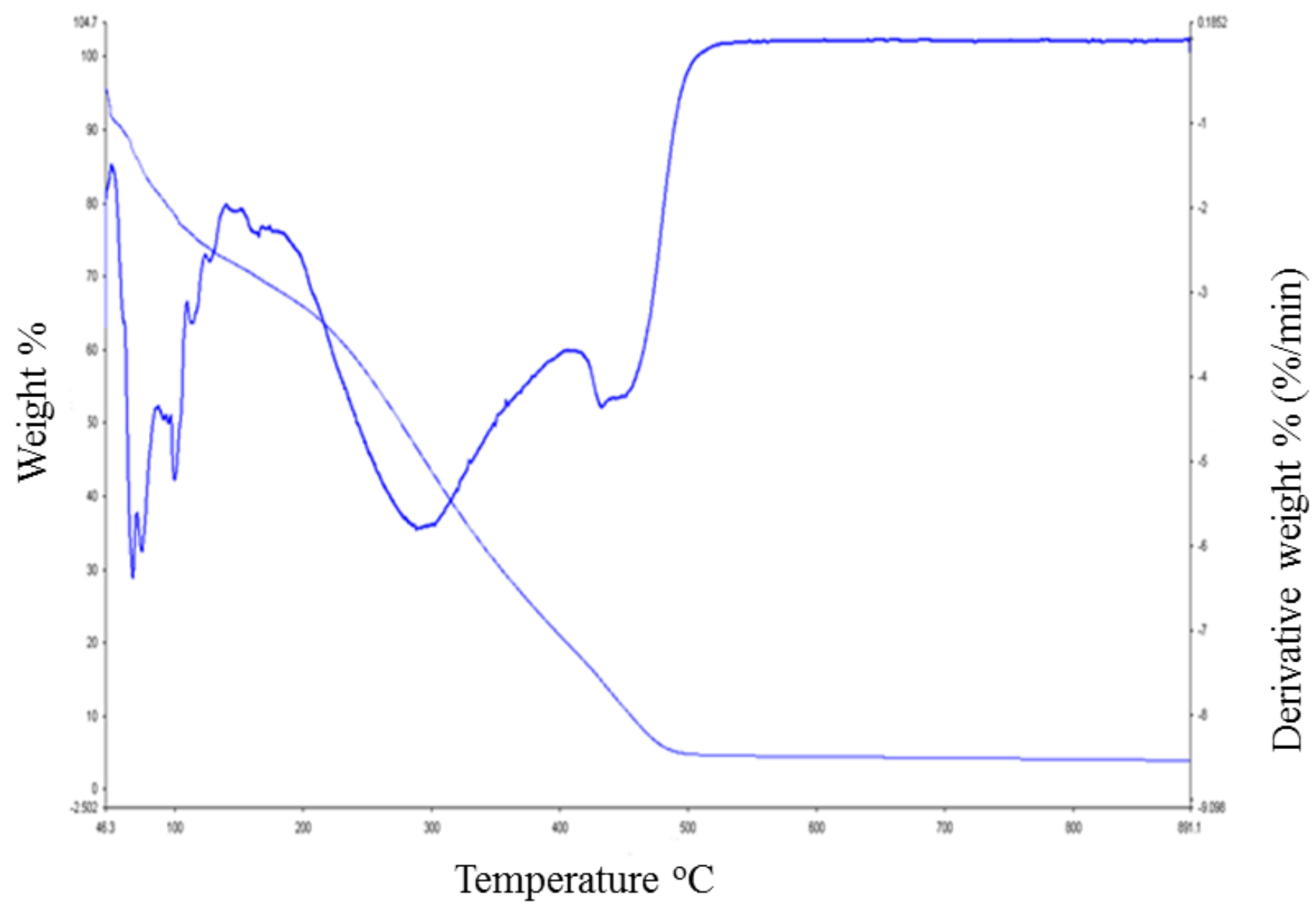

Figure 2: Mass loss curve of the extracted oil. 
In addition to magnesium chloride $\left(\mathrm{MgCl}_{2}\right)$, salts in crude oils consist of up to $75 \%$ sodium chloride $(\mathrm{NaCl})[60]$; typically the salinity of oil is measured as $\mathrm{NaCl}$ content. The salinity of the recovered oil was $2.30 \mathrm{mgl}^{-1}$. This value was slightly higher than the salt content of Hamada oil $\left(2.14 \mathrm{mgl}^{-1}\right)$. Comparing with other studies, this value was very low. Zubaidy and Abouelnasr [2] investigated the properties of 3 extracted oils and found the salt content to be 5, 7 and $196.4 \mathrm{mgl}^{-1}$ ). The presence of salts in oil is not favourable; even small concentrations of salt will accumulate in process equipment leading to fouling. In addition and more importantly, $\mathrm{NaCl}$ and $\mathrm{MgCl}_{2}$ can be hydrolysed to hydrochloric acid as indicated in the following equations:

$$
\begin{aligned}
& 2 \mathrm{NaCl}+\mathrm{H}_{2} \mathrm{O} \rightarrow 2 \mathrm{HCl}+\mathrm{Na}_{2} \mathrm{O} \\
& \mathrm{MgCl}_{2}+\mathrm{H}_{2} \mathrm{O} \rightarrow 2 \mathrm{HCl}+\mathrm{MgO}
\end{aligned}
$$

The produced hydrochloric acid is known to be extremely corrosive [42]. Ash content represents organic materials [61] and is another property used to assess the heating and calorific values of the oil $[28,62]$. The ash content in the recovered oil contains a higher ash $(0.007 \mathrm{~g} / \mathrm{g}$ oil $)$ than Hamada oil ( $0.004 \mathrm{~g} / \mathrm{g}$ oil). Previous studies confirm that lower ash content is indicative of high quality oil [63]; [28] studied the effects of ash content and found that presence of ash in oil reduces the heating value.

\section{Thermogravimetric analysis}

Thermogravimetric curve did not show decomposition stage at all temperatures as clearly shown in Differential Thermogravimetric (DTG curve) (Figure 2), however there was a sharp mass loss at the following temperatures: $66.82,74.03,89.40,101.96,114.73,129.37,146.07,161.39$, $289.28,431.48$, and $456.51^{\circ} \mathrm{C}$. The decomposition of crude oil at various temperatures shows the mass loss of hydrocarbons (low, medium and high molecular weight) respectively at $161.39,289.28,431.48,456.51^{\circ} \mathrm{C}$.
Figures 3 and 4 show the spectra obtained at various time intervals. EPA and NIST gas phase libraries were used to search/match the spectra obtained in this hyphenation experimentation and to compare the best possible match spectrum (Figures 5 and 6). The following are the gases evolved at various temperatures: methylene chloride, trans1,4-dimethylcyclohexane, cyclohexane1-hexyl4-tetradecyl, isobutyl cyclo-hexane and 1-ethyl 2-methylcyclohexane (Table 4). The spectra were obtained via search/match technique using EPA and NIST gas phase library. These values are matching similar to results published in the article Mothe et al in the article titled "Thermal Evaluation of Heavy Oils by Simultaneous TG/DTG/FTIR” [44].

\section{Dynamic shear rheology}

It has been observed that $1 \%$ is within the linear viscoelastic region of crude oil (internal bonds of the sample tested are intact at that strain value). Figure 7 shows the storage and loss moduli versus frequency: storage modulus $G^{\prime}$ values are higher than the values of loss modulus G". It can be inferred that crude oil sludge exhibits solid like behaviour (sludge) rather than the viscous liquid behaviour (oil). This behaviour could be due to the large solid particles present in the sludge. In general, it has been stated that crude oil exhibits more viscous liquid like behaviour than solid-like material. This change in rheological behaviour could be due to the presence of solid waste present in this oil. The viscosity of the crude oil decreases with increasing temperature as expected. It can be inferred from Figure 8 that the crude oil clearly exhibited a non-Newtonian behaviour (shear thinning) for the shear rate sweep between 10 and 500/s.

Figure 7 shows the storage and loss moduli of crude oil for a frequency sweep ( 1 to $100 \mathrm{rad} / \mathrm{s}$ ). The storage modulus and loss moduli increased with increase in angular frequency (1 to $100 \mathrm{rad} / \mathrm{s}$ ). Viscosity and other rheological parameters are very important for any

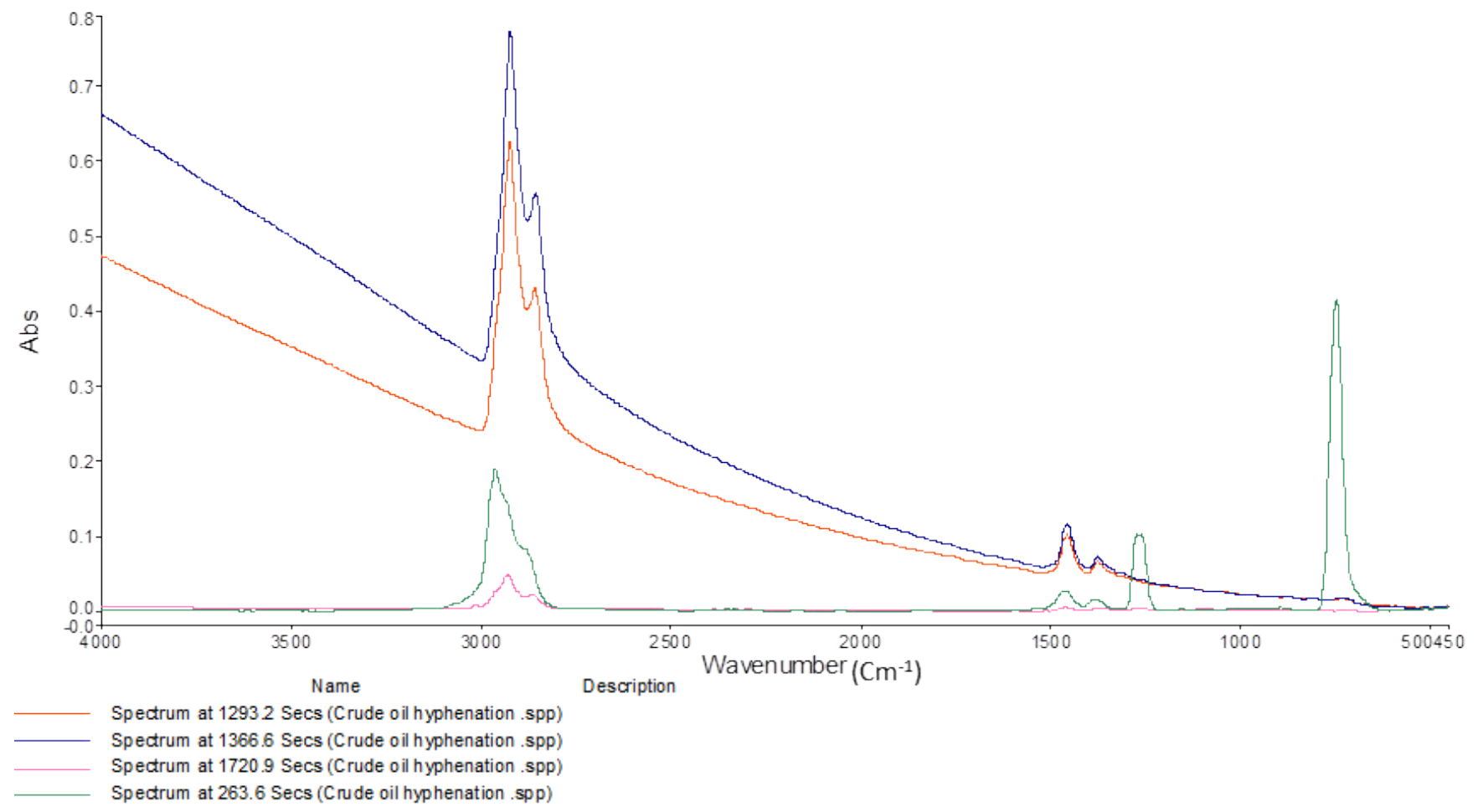

Figure 3: FTIR spectra collected at various time intervals. 


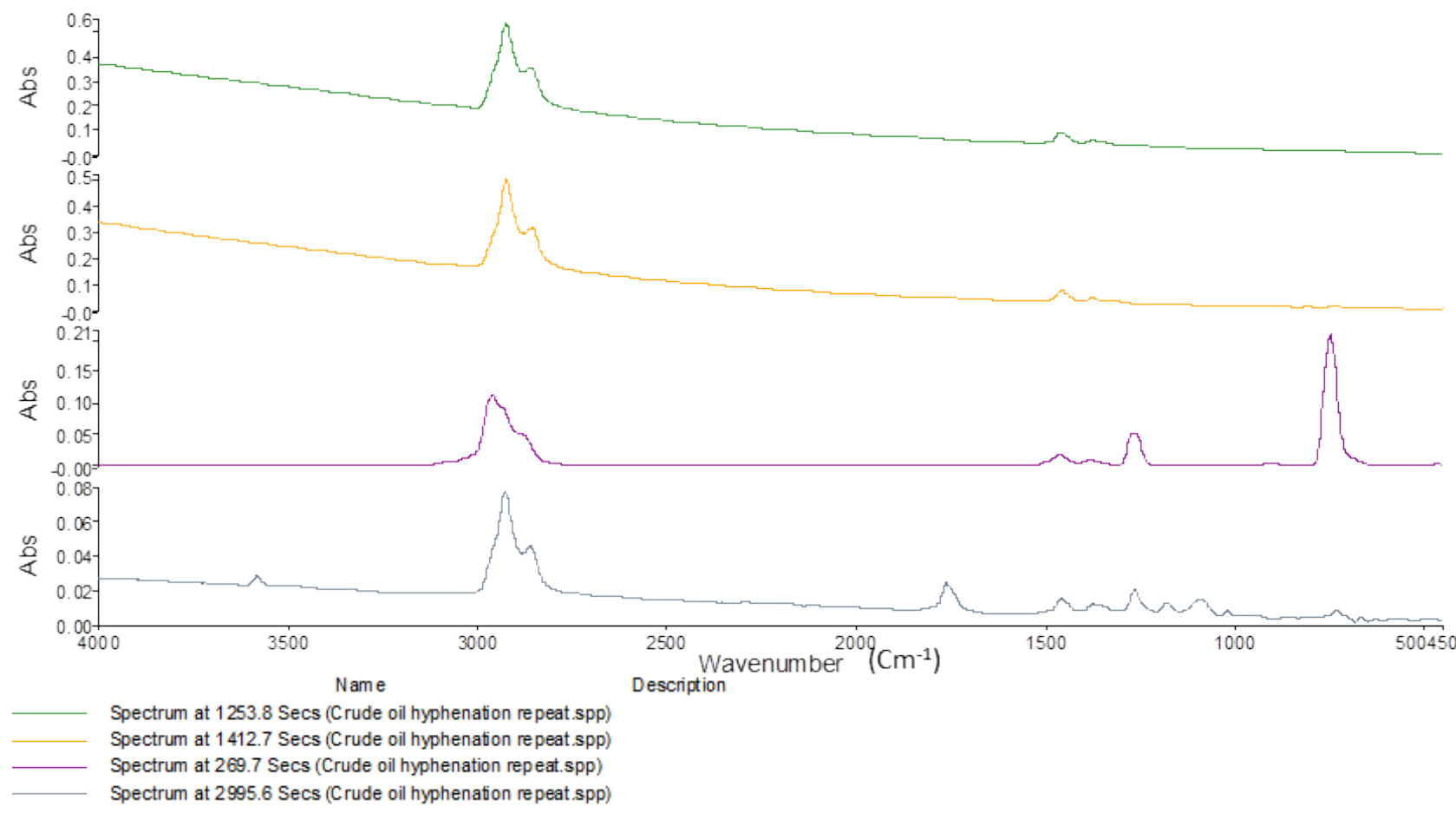

Figure 4: FTIR spectra collected at various time intervals.

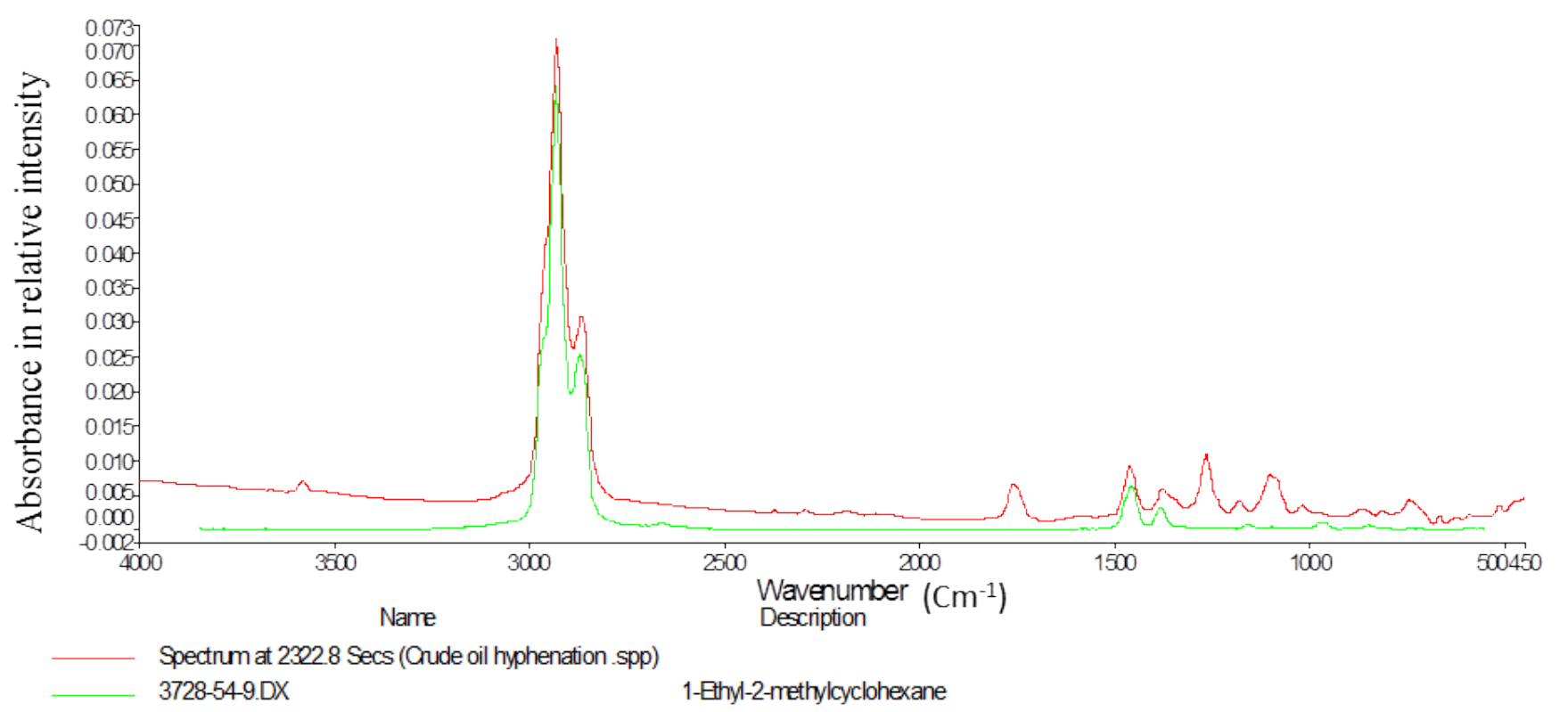

Figure 5: FTIR spectra collected at 2322 seconds compared with search match NIST and EPA vapour phase database.

liquids including materials like crude oil that are often transported via pipelines $[45,46,64]$. The transportation of crude oil is very challenging due to the high viscosity (medium and high molecular weight and low flowability). Figure 8 shows the viscosity over a temperature range (35 to $50^{\circ} \mathrm{C}$ ). The viscosity decreases with increasing temperature. The low and medium molar mass compounds tend to affect the bonds between the solid particles, eventually reducing the oil viscosity. Ghannam et al concluded that the decrease in viscosity with increase in temperature could be due to the effect of temperature on the chemical structure of the ingredients of the crude oil [45]. The change in viscosity over temperature could be attributed to changes in the chemical structure of high molecular mass components of the crude oil, in particular wax and asphalt [65].

For future work, the concentrations of heavy metals such as $\mathrm{P}, \mathrm{Cd}$, 


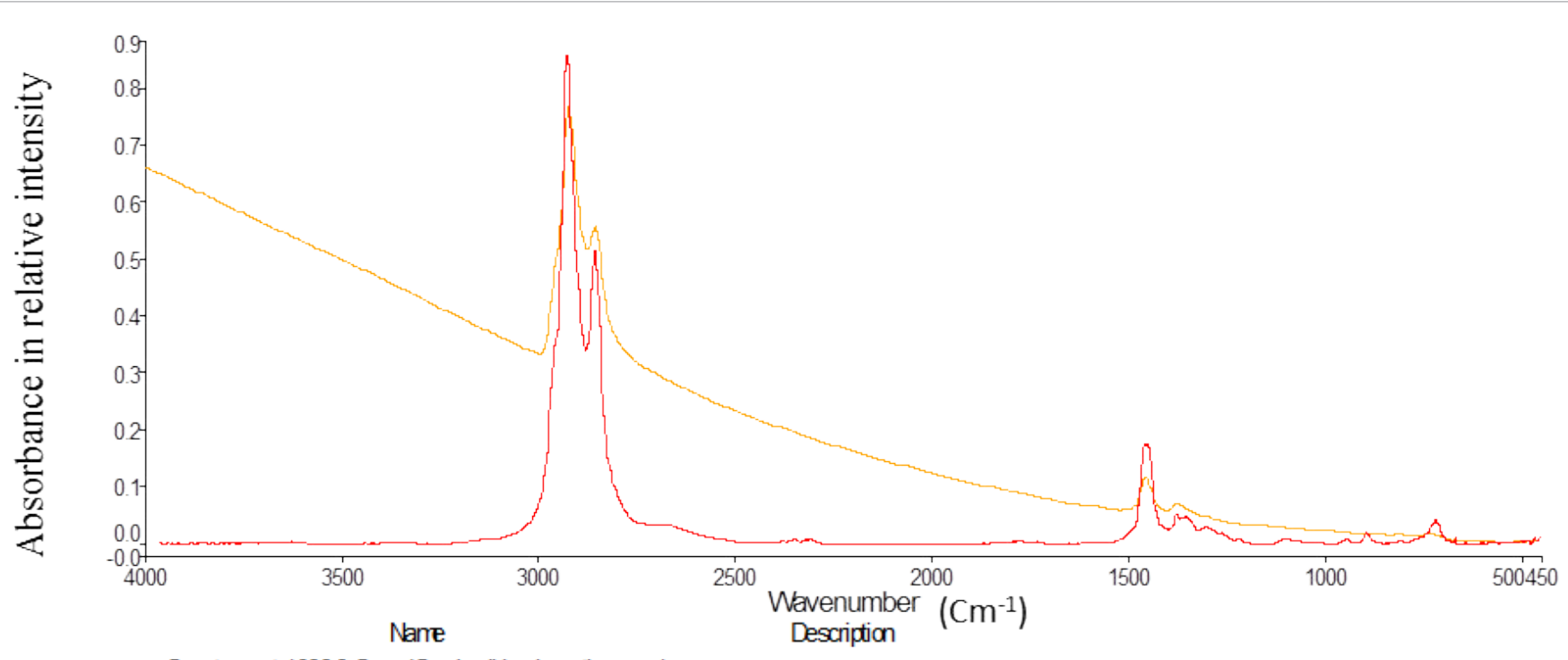

Spectruma 13666 Secs (Crude oil hyphenation .spp) 6836-35-7.DX

Oyclohexane, 1-dodecyl-4-octyl-,

Figure 6: FTIR spectra collected at 1366 seconds compared with search match NIST and EPA vapour phase database.

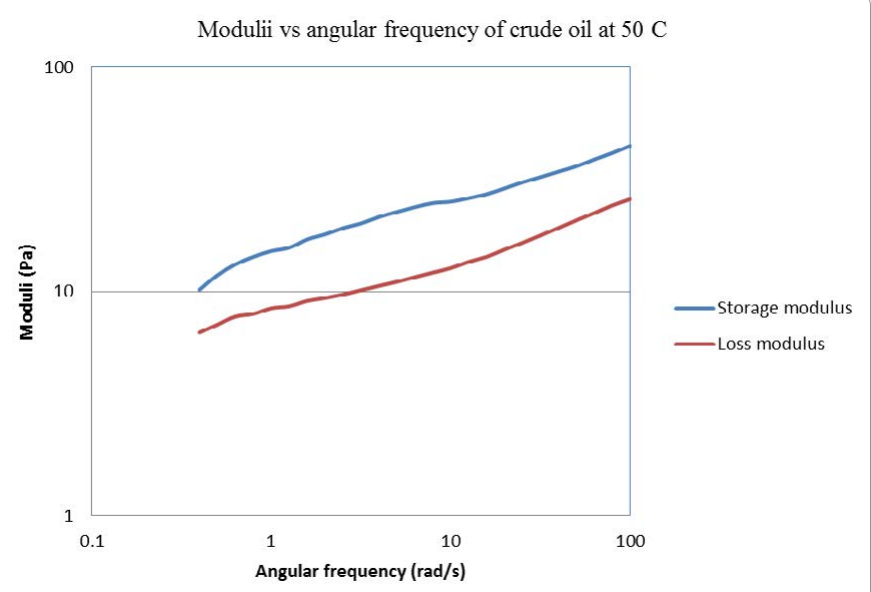

Figure 7: Angular frequency (storage and loss moduli) at $50^{\circ} \mathrm{C}$.

$\mathrm{Cr}, \mathrm{Cu}, \mathrm{Ni}, \mathrm{Pb}, \mathrm{Zn}$ and $\mathrm{Fe}$ can be carried out. This can be determined using inductively coupled plasma optical emission spectrometry (ICPOES) (Optima 2000DV; Perkin Elmer, Waltham, MA, USA) (detection limit 0.001-0.030 $\left.\mathrm{mgl}^{-1}\right)$ and inductively coupled plasma-mass spectrometry (ICP-MS) (7500a; Agilent Technologies, Santa Clara, CA, USA) (detection limit 0.015-0.120 $\mathrm{mgl}^{-1}$ ) [66]. In addition, luminescent iridium (III) complex-base chemosensor and probes can be used to detect the heavy metals ions $[67,68]$. Moreover, logic gates technique is one of the useful tool that respond to the ions of metal $[69,70]$.

\section{Conclusion}

The purpose of this study was (i) to extract oil from Libyan COTBS and present the most important properties through a qualitative and quantitative assessment and to compare it with the parent oil (Hamada crude oil), and (ii) to reduce the oil content of the sludge to the minimum level to reduce the environmental impact of COTBS. Some important properties of the COTBS were studied (Table 1). To determine the applicability of recovered oil for use as feedstock for

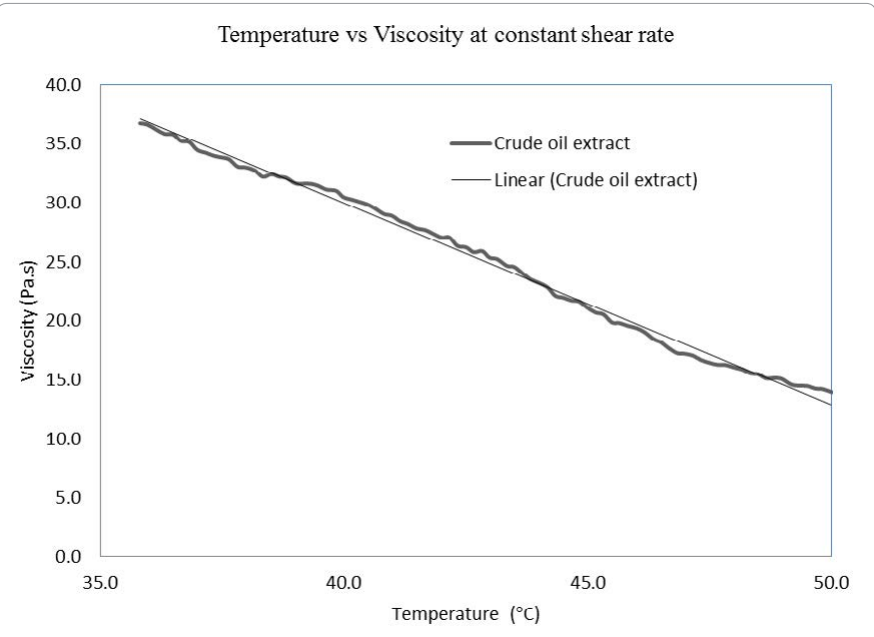

Figure 8: Temperature vs. viscosity profile.

recycling, the physiochemical properties were investigated (Table 2). The extraction yield confirmed that the oil content of COTBS was significant (42.08\%). GC-MS analysis of the recovered oil indicated that the oil contained hydrocarbon fractions in the range of $\mathrm{C}_{14}-\mathrm{C}_{24}$ with TPH and PAHs concentrations of $29,367 \mathrm{mgkg}^{-1}$ and $11,752 \mathrm{mgkg}^{-1}$ respectively. Comparing the properties of the recovered oil with the parent oil which was the original source of this sludge and classified as light oil, the reclaimed oil was heavier. Lower LHF content decreased the API gravity (33.03), but the API still higher than (31.1) meaning that the reclaimed oil is light oil. Consequently, the recovered oil can be classified as light oil and potentially used as good feedstock oil. The candidate (crude oil) exhibits non-Newtonian shear thinning behaviour over the shear rates sweep between 10 and 500/s. Viscosity of crude oil decreases significantly with increase in temperature due to the effect of temperature on chemical structure of the ingredient of the crude oil. This is the first report of the oil recovery from COTBS from Libya having significant potential of oil for use in the oil industry. 


\section{Acknowledgement}

This work was supported by the Libyan Ministry of Higher Education and Science Research. The authors thank the Environmental and Natural Resources Engineering, faculty of engineering. Sabratah. Azawia University- Libya, the management of Azzawiya oil refinery- Libya and brother Ali Mansour for his unlimited support and supplying soil and COTBS samples.

\section{References}

1. Kilian L, Lee TK (2014) Quantifying the speculative component in the real price of oil: The role of global oil inventories. Journal of International Money and Finance 42: 71-87.

2. Zubaidy EA, Abouelnasr DM (2010) Fuel recovery from waste oily sludge using solvent extraction. Process Safety and Environmental Protection 88: 318-326.

3. Giles HN, Koenig JJ, Neihof RA, Shay JY, Woodward PW (1991) Stability of refined products and crude oil stored in large cavities in salt deposits: Biogeochemical aspects. Energy \& fuels 5: 602-608.

4. Hu G, Li J, Zeng G (2013) Recent development in the treatment of oily sludge from petroleum industry: a review. J Hazard Mater 261: 470-490.

5. Saikia M, Bora M, Dutta N (2003) Oil recovery from refinery sludge-a case study. Chemcon CHM 27.

6. Sanders DA, Veenstra JN (2001) Pollution prevention and reuse alternatives for crude oil tank bottom sludges. Proceedings of the 8th international petroleum environmental conference, Houston, USA

7. Ramaswamy B, Kar DD, De S (2007) A study on recovery of oil from sludge containing oil using froth flotation. J Environ Manage 85: 150-154.

8. Striegel J, Sanders DA, Veenstra JN (2001) Treatment of contaminated groundwater using permeable reactive barriers. Environmental Geosciences 8: 258-265.

9. Ward O, Singh A, Van Hamme J (2003) Accelerated biodegradation of petroleum hydrocarbon waste. J Ind Microbiol Biotechnol 30: 260-270.

10. Liu J, Jiang X, Han X (2011) Devolatilization of oil sludge in a lab-scale bubbling fluidized bed. J Hazard Mater 185: 1205-1213.

11. Du W, Wan Y, Zhong N, Fei J, Zhang Z, et al. (2011) Status quo of soil petroleum contamination and evolution of bioremediation. Petroleum Science 8: 502-514.

12. Kam EK (2001) Assessment of sludges and tank bottoms treatment processes. Proceedings of the 8th international petroleum environmental conference, Houston, USA.

13. Jing G, Luan M, Du W, Han C (2012) Treatment of oily sludge by advanced oxidation process. Environmental Earth Sciences 67: 2217-2221.

14. Avilachavez MA, Eustaquio-Rincon R, Reza J, Trejo A (2007) Extraction of hydrocarbons from crude oil tank bottom sludges using supercritical ethane. Separation Science and Technology 42: 2327-2345.

15. Liu W, Luo Y, Teng Y, Li Z, Christie P (2009) Prepared bed bioremediation of oily sludge in an oilfield in northern China. J Hazard Mater 161: 479-484

16. Lin GH, Sauer NE, Cutright TJ (1996) Environmental regulations: a brief overview of their applications to bioremediation. International biodeterioration \& biodegradation 38: 1-8.

17. Zhang J, Li J, Thring RW, Hu X, Song X (2012) Oil recovery from refinery oily sludge via ultrasound and freeze/thaw. J Hazard Mater 203-204: 195-203.

18. da Silva LJ, Alves FC, de França FP (2012) A review of the technological solutions for the treatment of oily sludges from petroleum refineries. Waste Manag Res 30: 1016-1030.

19. Jin $Y$, Zheng $X$, Chu $X$, Chi $Y$, Yan J, et al. (2012) Oil recovery from oil sludge through combined ultrasound and thermochemical cleaning treatment. Industrial \& Engineering Chemistry Research 51: 9213-9217.

20. Buyukkamaci N, Kucukselek E (2007) Improvement of dewatering capacity of a petrochemical sludge. J Hazard Mater 144: 323-327

21. Shie JL, Chang CY, Lin JP, Wu CH, Lee DJ (2000) Resources recovery of oil sludge by pyrolysis: kinetics study. Journal of Chemical Technology and Biotechnology 75: 443-450.

22. Mishra S, Jyot J, Kuhad RC, Lal B (2001) Evaluation of inoculum addition to stimulate in situ bioremediation of oily-sludge-contaminated soil. Appl Environ Microbiol 67: 1675-1681.
23. Liu W, Luo Y, Teng Y, Li Z, Ma LQ (2010) Bioremediation of oily sludgecontaminated soil by stimulating indigenous microbes. Environ Geochem Health 32: 23-29.

24. Pusch G, Gaida KH (1981) Method of recovering petroleum and bitumen from subterranean reservoirs. Google Patents US4252191 A.

25. Centeno G, Sanchez-reyna G, Ancheyta J, Munoz JA, Cardona N (2011) Testing various mixing rules for calculation of viscosity of petroleum blends. Fuel 90: 3561-3570.

26. Hasan SW, Ghannam MT, Esmail N (2010) Heavy crude oil viscosity reduction and rheology for pipeline transportation. Fuel 89: 1095-1100.

27. Gharagheizi F, Tirandazi B, Barzin R (2008) Estimation of aniline poin temperature of pure hydrocarbons: A quantitative structure property relationship approach. Industrial \& Engineering Chemistry Research 48: 1678-1682.

28. Biller P, Ross AB (2011) Potential yields and properties of oil from the hydrothermal liquefaction of microalgae with different biochemical content. Bioresour Technol 102: 215-225.

29. Gary JH, Handwerk GE, Kaiser MJ (2010) Petroleum refining: technology and economics, CRC press.

30. Mansur A, Adetutu E, Kadali K, Morrison P, Nurulita Y, et al. (2014) Assessing the hydrocarbon degrading potential of indigenous bacteria isolated from crude oil tank bottom sludge and hydrocarbon-contaminated soil of Azzawiya oil refinery, Libya. Environ Sci Pollut Res Int 21: 10725-10735.

31. Joseph PJ, Joseph A (2009) Microbial enhanced separation of oil from petroleum refinery sludge. J Hazard Mater 161: 522-525.

32. Taiwo E, Otolorin $\mathrm{J}$ (2009) Oil recovery from petroleum sludge by solvent extraction. Petroleum Science and Technology 27: 836-844.

33. Pradhan P, Giri J, Rieken F, Koch C, Mykhaylyk O, et al. (2010) Targeted temperature sensitive magnetic liposomes for thermo-chemotherapy. J Control Release 142: 108-121.

34. Garcia-Perez M, Shen J, Wang XS, Li CZ (2010) Production and fuel properties of fast pyrolysis oil/bio-diesel blends. Fuel Processing Technology 91: 296-305

35. Sabate J, Vinas M, Solanas A (2004) Laboratory-scale bioremediation experiments on hydrocarbon-contaminated soils. International Biodeterioration \& Biodegradation 54: 19-25.

36. Demirbas A (2008) Relationships derived from physical properties of vegetable oil and biodiesel fuels. Fuel 87: 1743-1748.

37. Yuying L, Bing L (2011) The Changes of Crude Oil during Evaporation Process in Environment. Bioinformatics and Biomedical Engineering, 5th International Conference on IEEE, 1-4.

38. Tat ME, Van Gerpen JH (1999) The kinematic viscosity of biodiesel and its blends with diesel fuel. Journal of the American Oil Chemists' Society 76: 1511 1513.

39. Noureddini H, Teoh B, Clements LD (1992) Viscosities of vegetable oils and fatty acids. Journal of the American Oil Chemists Society 69: 1189-1191.

40. Xu Y, Lu M (2010) Bioremediation of crude oil-contaminated soil: comparison of different biostimulation and bioaugmentation treatments. J Hazard Mater 183 395-401.

41. Fortuny M, Oliveira CB, Melo RL, Nele M, Coutinho RC, et al. (2007) Effect of salinity, temperature, water content, and $\mathrm{pH}$ on the microwave demulsification of crude oil emulsions. Energy \& fuels 21: 1358-1364.

42. Speight JG, Speight J (2002) Handbook of petroleum product analysis, WileyInterscience, New Jersey, USA.

43. Wilkie CA (1999) TGA/FTIR: an extremely useful technique for studying polymer degradation. Polymer Degradation and Stability 66: 301-306.

44. Michelle Mothe CM, Carvalho CH (2013) Thermal Evaluation of Heavy Oils by Simultaneous TG/DTG/FTIR. 41st Annual Conference of the North American Thermal Analysis Society.

45. Ghannam MT, Hasan SW, Abu-Jdayil B, Esmail N (2012) Rheologica properties of heavy \& light crude oil mixtures for improving flowability. Journal of Petroleum Science and Engineering 81: 122-128.

46. Evdokimov IN, Eliseev DY (2001) Rheological evidence of structural phase transitions in asphaltene-containing petroleum fluids. J Pet Sci Eng 199-211. 
Citation: Mansur AA, Pannirselvam M, Al-Hothaly KA, Adetutu EM, Ball AS (2015) Recovery and Characterization of Oil from Waste Crude Oil Tank Bottom Sludge from Azzawiya Oil Refinery in Libya. J Adv Chem Eng 5: 118. doi: 10.4172/2090-4568.1000118

Page 11 of 11

47. Heidarzadeh N, Gitipour S, Abdoli MA (2010) Characterization of oily sludge from a Tehran oil refinery. Waste Manag Res 28: 921-927.

48. Wang J, Yin J, Ge L, Shao J, Zheng J (2010) Characterization of oil sludges from two oil fields in China. Energy \& Fuels 24: 973-978.

49. Elektorowicz M, Habibi S (2005) Sustainable waste management: recovery of fuels from petroleum sludge. Canadian Journal of Civil Engineering 32: 164169

50. Xiaoxue HSLZL (2002) The Current Status of Oily Sludge and its Treatment Technique in Gudong Oil field. J Environmental Protection of Oil \& Gas Fields 1: 007.

51. American Petroleum Institute (1989) Category Assessment Document for Reclaimed Petroleum Hydrocarbon: Residual Hydrocarbon Waste from Petroleum Refining. In: Program UEHC (ed.) Washington DC, USA.

52. American Petroleum Institute (1992) API Environmental Guidance Document Onshore Solid Waste Msanagment in Exploration and Petroleum Operations. Washing DC, USA.

53. Hahn W (1994) High-temperature reprocessing of petroleum oily sludges. SPE Production \& Facilities 9: 179-182.

54. Poulsen MM, Kueper BH (1992) A field experiment to study the behavior of tetrachloroethylene in unsaturated porous media. Environmental science \& technology 26: 889-895.

55. Al-Futaisi A, Jamrah A, Yaghi B, Taha R (2007) Assessment of alternative management techniques of tank bottom petroleum sludge in Oman. J Hazard Mater 141: 557-564.

56. Zhang Q, Chang J, Wang T, Xu Y (2007) Review of biomass pyrolysis oil properties and upgrading research. Energy conversion and management 48 87-92.

57. Gregoli AA, Rimmer DP (2000) Production of synthetic crude oil from heavy hydrocarbons recovered by in situ hydrovisbreaking. Google Patents, US $6016867 \mathrm{~A}$.

58. Martínez-Palou R, Mosqueira MDL, Zapata-Rendón B, Mar-Juárez, E, BernalHuicochea C, et al. (2011) Transportation of heavy and extra-heavy crude oil by pipeline: A review. Journal of Petroleum Science and Engineering 75: 274-282.
59. Johnson LA, Lusas E (1983) Comparison of alternative solvents for oils extraction. Journal of the American Oil Chemists' Society 60: 229-242.

60. Guedes Soares C, Garbatov Y, Zayed A, Wang G (2008) Corrosion wastage model for ship crude oil tanks. Corrosion Science 50: 3095-3106.

61. Vardon DR, Sharma BK, Scott J, Yu G, Wang Z, et al. (2011) Chemical properties of biocrude oil from the hydrothermal liquefaction of Spirulina algae, swine manure, and digested anaerobic sludge. Bioresour Technol 102: 82958303.

62. Anastasakis K, Ross AB (2011) Hydrothermal liquefaction of the brown macroalga Laminaria saccharina: effect of reaction conditions on product distribution and composition. Bioresour Technol 102: 4876-4883.

63. Sarma AK, Konwer D, Bordoloi P (2005) A comprehensive analysis of fue properties of biodiesel from Koroch seed oil. Energy \& fuels 19: 656-657.

64. Marchesini FVH, Alicke AA, De Souza Mendes PR, Ziglio CUM (2012) Rheological characterization of waxy crude oils: sample preparation. Energy \& Fuels 26: 2566-2577.

65. Khan MR (2007) Rheological Properties of Heavy Oils and Heavy Oi Emulsions. 385-391.

66. Tang W, Shan B, Zhang H, Zhang W, Zhao Y, et al. (2014) Heavy metal contamination in the surface sediments of representative limnetic ecosystems in eastern China. Sci Rep 4: 7152.

67. Ma DL, He HZ, Zhong HJ, Lin S, Chan DS, et al. (2014) Visualization of Zn ions in live zebrafish using a luminescent iridium(III) chemosensor. ACS App Mater Interfaces 6: 14008-14015.

68. He HZ, Leung KH, Yang H, Chan DS, Leung CH, et al. (2013) Label-free detection of sub-nanomolar lead(II) ions in aqueous solution using a metalbased luminescent switch-on probe. Biosens Bioelectron 41: 871-874.

69. Ma DL, He HZ, Chan DSH, Leung CH (2013) Simple DNA-based logic gates responding to biomolecules and metal ions. Chemical Science 4: 3366-3380.

70. Ramachandran SD, Sweezey MJ, Hodson PV, Boudreau M, Courtenay SC, et al. (2006) Influence of salinity and fish species on PAH uptake from dispersed crude oil. Mar Pollut Bull 52: 1182-1189. 